\begin{tabular}{|c|l|}
\hline Title & Nickel-Promoted Carboxylation/Cyclization Cascade of A llenyl A Idehyde under an A tmosphere of C02 \\
\hline Author(s) & Takimoto, Masanori; Kawamura, Mitsunobu; Mori, Miwako; Sato, Yoshihiro \\
\hline Citation & $\begin{array}{l}\text { Synlett, 2011(10), 1423-1426 } \\
\text { https://doi.org/10.1055/s0030-1260565 }\end{array}$ \\
\hline Issue Date & 2011-06 \\
\hline Doc URL & http://hdl.handle.net/2115/49337 \\
\hline Rights & ○ 2011 Georg Thieme Verlag \\
\hline Type & article (author version) \\
\hline File Information & Syn2011-10_1423-1426.pdf \\
\hline
\end{tabular}

Instructions for use 


\title{
Nickel-Promoted Carboxylation/Cyclization Cascade of Allenyl Aldehyde Under an Atmosphere of $\mathbf{C O}_{2}$
}

\author{
Masanori Takimoto, ${ }^{\dagger}$ Mitsunobu Kawamura, Miwako Mori, and Yoshihiro Sato* \\ Faculty of Pharmaceutical Sciences, Hokkaido University, Sapporo 060-0812, Japan \\ E-mail: biyo@pharm.hokudai.ac.jp \\ Received: The date will be inserted once the manuscript is accepted.
}

\begin{abstract}
In the presence of a stoichiometric amount of $\mathrm{Ni}(0)$ complex, allenyl aldehydes smoothly reacted with carbon dioxide at an ambient temperature and pressure in a regioselective manner. The reaction involves an intramolecular cyclization of aldehyde and allene moieties to afford cyclic carboxylic acid derivatives having a hydroxyl group.
\end{abstract}

Key words: allenes, aldehydes, carboxylic acid, cyclization, nickel

Development of new methods to incorporate carbon dioxide $\left(\mathrm{CO}_{2}\right)$ into organic molecules through carboncarbon bond formations is still an important subject in synthetic organic chemistry. With the aim of developing novel $\mathrm{CO}_{2}$ incorporation reactions, transition-metalpromoted carboxylation reaction has attracted much attention. ${ }^{1,2}$ Nickel-mediated or -catalyzed coupling reactions of $\mathrm{CO}_{2}$ with unsaturated hydrocarbons have been extensively investigated recently. ${ }^{3}$ Such nickelmediated processes are attractive not only because they can be conducted under mild conditions but also because they can produce reactive intermediates that are usable for further carbon-carbon bond formation. In this letter, we report a nickel-promoted $\mathrm{CO}_{2}$ incorporation reaction into allenyl aldehydes that involves an intramolecular carbon-carbon bond formation between the allene and aldehyde moieties. ${ }^{4,5}$

In the course of our previous studies on nickel-promoted or -catalyzed $\mathrm{CO}_{2}$ incorporation reactions, ${ }^{4}$ we found that various allenes reacted with $\mathrm{CO}_{2}$ and a zero-valent nickel complex to form a nucleophilic oxa-nickelacycle that could react with aldehydes. ${ }^{4 \mathrm{e}}$ From these results, we envisioned a carboxylation/cyclization cascade of allenyl aldehyde 1, which would proceed according to the following reaction process: (i) oxidative cyclization of $\mathbf{1}$ and $\mathrm{CO}_{2}$ with low-valent nickel species would afford an oxa-nickelacycle $2^{6}$ and (ii) intramolecular nucleophilic addition of the oxa-nickelacycle moiety of $\mathbf{2}$ to the tethered aldehyde would give cyclized product $\mathbf{3}$ (Scheme 1). ${ }^{7}$

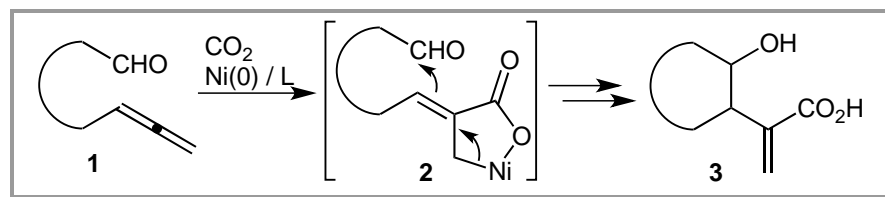

Scheme 1 Carboxylation/Cyclization cascade

We first examined nickel-promoted carboxylation of the allenyl aldehyde 1a under standard conditions previously developed by us for nickel-promoted $\mathrm{CO}_{2}$ incorporation reactions. To our delight, the reaction of $1 \mathbf{a}$ with $\mathrm{CO}_{2}(1$ atm) proceeded in THF at room temperature in the presence of $\mathrm{Ni}(\mathrm{cod})_{2}$ (1 equiv) and 1,8-diazabicyclo[5.4.0] undec-7-ene (DBU, 2 equiv) (Scheme 2). After hydrolysis of the reaction mixture followed by diazomethane esterification, the desired cyclic carboxylic acid ester 3a was isolated in 50\% yield. Treatment of 3a with $\mathrm{NaH}$ afforded bicyclic $\alpha$ methylene lactone $\mathbf{4 a}$ in $92 \%$ yield. The observed coupling constant value between $\mathrm{H}_{\mathrm{a}}$ and $\mathrm{H}_{\mathrm{b}}$ in the ${ }^{1} \mathrm{H}$ NMR spectrum of $\mathbf{4 a}$ showed that $\mathbf{4 a}$ had a trans-fused bicyclic structure, and thus the configuration of the hydroxyl group and alkenyl moiety on 3a was determined to be trans.

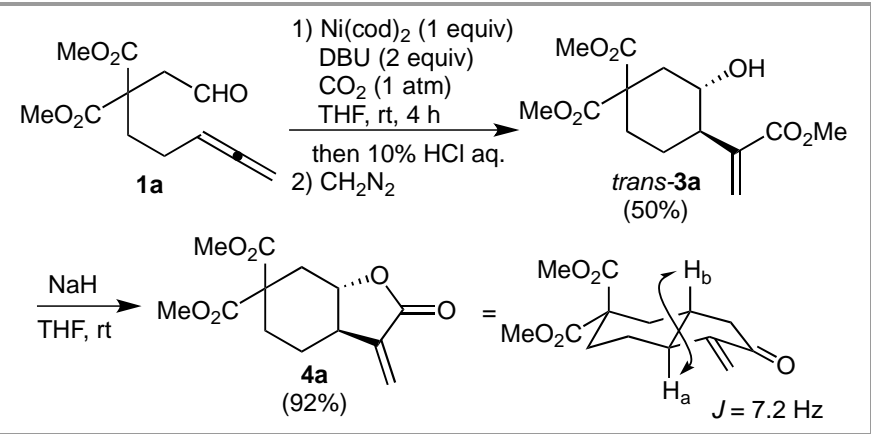

Scheme 2

To improve the yield of $\mathbf{3 a}$, various reaction conditions were examined (Table 1).

\section{Table 1 Carboxylative Cyclization of 1a under Various Conditions ${ }^{a}$}

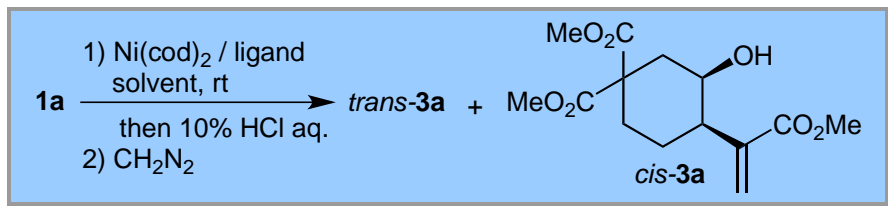

\begin{tabular}{llllllll}
\multirow{2}{*}{ entry } & solvent & ligand & time (h) & \multicolumn{3}{c}{ yields of 3a (\%) } \\
& & & & trans & cis & total \\
\hline 1 & toluene & $\mathrm{DBU}^{b}$ & 3 & 42 & - & 42 \\
2 & DMF & $\mathrm{DBU}^{b}$ & 3 & 52 & - & 52 \\
3 & dioxane & $\mathrm{DBU}^{b}$ & 4 & 57 & - & 57 \\
4 & dioxane & $\mathrm{DBN}^{b}$ & 1 & 45 & - & 45 \\
5 & dioxane & $\mathrm{bpy}^{c}$ & 2 & 17 & - & 17 \\
6 & dioxane & $\mathrm{DMI}^{b}$ & 2 & 27 & - & 27 \\
7 & dioxane & $\mathrm{TMEDA}^{c}$ & 3 & 59 & 28 & 87
\end{tabular}

${ }^{a}$ The reactions were carried out using 1 equiv of $\mathrm{Ni}(\mathrm{cod})_{2}$ under an atmosphere of $\mathrm{CO}_{2}(1 \mathrm{~atm}) .{ }^{b} 2$ equiv to $\mathrm{Ni}(\operatorname{cod})_{2}$. ${ }^{c} 1$ equiv to $\mathrm{Ni}(\operatorname{cod})_{2}$ 
Among the solvents examined (entries 1-3), 1,4-dioxane, a relatively polar solvent gave the best result (entry 3). The effects of ligands were also investigated when dioxane was used as the solvent (entries 5-6). The use of DBN, 1,2-bipyridine (bpy) or 1,2-dimethylimidazole (DMI) did not result in any significant improvement compared with DBU. Interestingly, by using tetramethylethylene diamine (TMEDA) as the ligand, the total yield of the cyclized products was improved to $87 \%$, although cis-3a was also formed in $28 \%$ yield along with trans-3a. $^{8}$

The reaction of $\mathbf{1 b}$ with $\mathrm{CO}_{2}$ proceeded smoothly in the presence of $\mathrm{Ni}(\mathrm{cod})_{2}$ and TMEDA at room temperature to give the desired cyclic product with a five-membered ring (Scheme 3). Because the formed carboxylic acid easily underwent dehydration during the purification process, the product was isolated and characterized as $\mathbf{4 b}$ (61\% yield from 1b) after lactonization in the presence of an acid catalyst. From the results of NOE experiments, the stereochemistry of $\mathbf{4 b}$ was determined to be cis, as shown in Scheme 3.

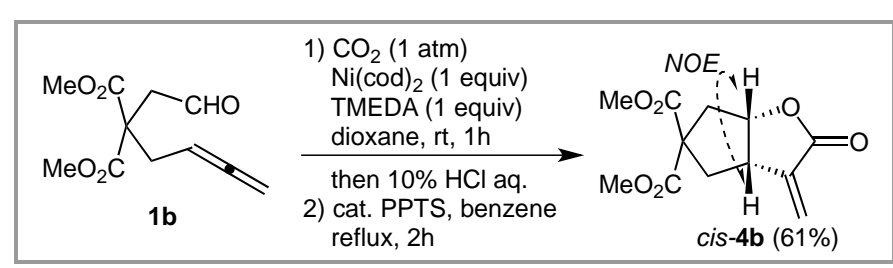

Scheme 3

In contrast, seven-membered ring formation from 1c was sluggish under similar conditions, and simply carboxylated product 5c was obtained in 45\% (Scheme 4, eq. 1). This result indicated that the reaction did not proceed further from intermediate 2c. However, fortunately, we found that the use of $\mathrm{ZnCl}_{2}$ (3 equiv to 1c) as an additive promoted the desired cyclization process to afford lactone cis-4c in $41 \%$ yield (Scheme 4 , eq. 2). The use of other Lewis acids, including $\mathrm{BF}_{3}$ and TMSOTf, did not work well as promoters. These results suggest that $\mathrm{ZnCl}_{2}$ did not simply act as a Lewis acid but also as a transmetalating reagent to form a more nucleophilic $\pi$-allylnickel chloride such as $6 \mathbf{c}^{9}{ }^{9}$

With this knowledge in hand, we tried to apply the present carboxylation/cyclization cascade for the synthesis of heterocyclic and benzene-fused bicyclic compounds, and the results are summarized in Table 2.

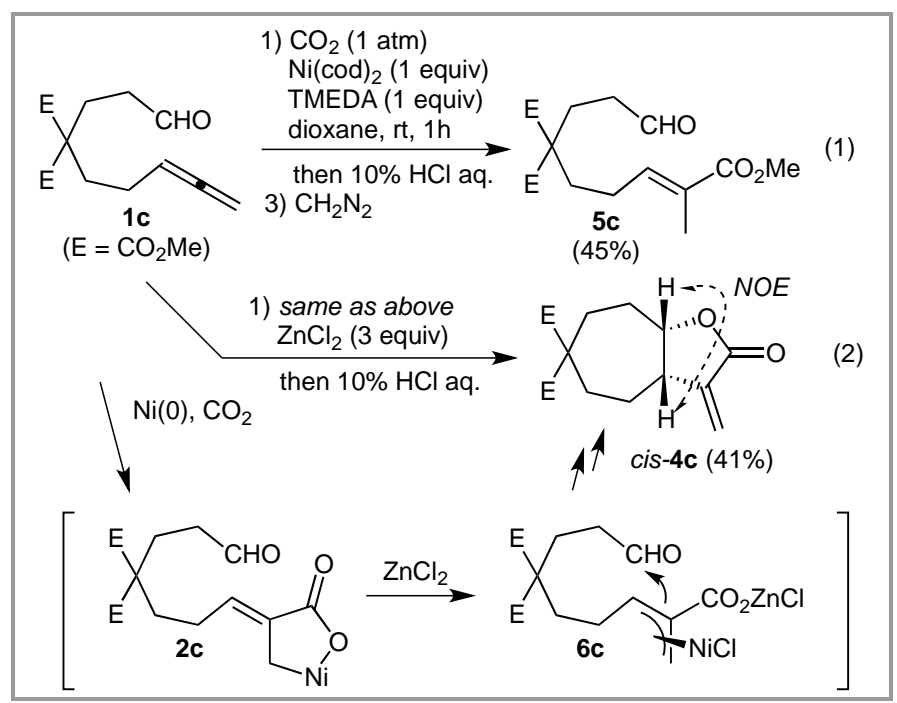

Scheme 4

Table 2 Carboxylative Cyclization of $\mathbf{1 d}-\mathbf{h}^{a}$ entry

$1^{c}$<smiles>C=CCC[18N][Ga]=O</smiles>

$\begin{array}{ll}\text { time } & \text { products } \\ \text { (h) } & \text { (trans / cis) }\end{array}$

1

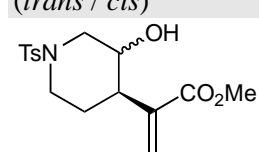

1d $(\mathrm{n}=1)$

3d $(65$ / 9)

$2^{d} \quad \mathbf{1 e}(\mathrm{n}=2)$

2

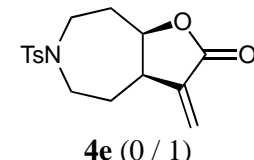

33

$3^{c}$<smiles>[R]C=CC=Cc1ccccc1C=O</smiles>

1<smiles>C=C(C(C)=O)[C@H]1CCc2ccccc2[C@H]1O</smiles>

$4^{c} \quad \mathbf{1 g}(\mathrm{R}=\mathrm{Ph})$

2<smiles>CC(=O)/C(=C/c1ccccc1)C1CCc2ccccc2[C@H]1O</smiles>

$5^{c} \quad \mathbf{1 h}(\mathrm{R}=\mathrm{Me})$<smiles>C/C=C(/C)C1CCc2ccccc2[C@@H]1O</smiles>

$3 h(63 / 11)$

${ }^{a}$ The reactions were carried out using $\mathrm{Ni}(\mathrm{cod})_{2}$ (1 equiv) and TMEDA (1 equiv) in dioxane under an atmosphere of $\mathrm{CO}_{2}(1 \mathrm{~atm}) .{ }^{b}$ The ratio was determined by ${ }^{1} \mathrm{H}$ NMR. For determination of the stereochemistry of the products, see Supporting Information. ${ }^{c}$ The crude products were treated with $\mathrm{CH}_{2} \mathrm{~N}_{2}$ for esterification. ${ }^{d}$ The crude products were treated with PPTS in benzene for lactonization.

Carboxylative cyclization of $\mathbf{1 d}$ with $\mathrm{CO}_{2}$ in the presence of a stoichiometric amount of $\mathrm{Ni}(\mathrm{cod})_{2}$ and TMEDA proceeded smoothly to afford the desired cyclized product $3 \mathbf{d}$ in $74 \%$ yield as a mixture of two stereo isomers. Although $\mathrm{ZnCl}_{2}$ was necessary, carboxylation of 1 e also gave the desired product $\mathbf{4 e}$ in $33 \%$ yield. 
Furthermore, the present system was applicable to the synthesis of benzene-fused bicyclic compounds (Table 2 entry 3-5). Benzaldehyde derivative 1f, having a terminal allene moiety at the ortho position, smoothly reacted with $\mathrm{CO}_{2}$ under similar conditions to afford $\mathbf{3 f}$ in $66 \%$ yield. Interestingly, in the reactions of $\mathbf{1 g}$ and $\mathbf{1 h}$ having an internal allene moiety, the cyclization process proceeded to give $\mathbf{3 g}$ and $\mathbf{3 h}$ in $66 \%$ and $74 \%$ yields, respectively. In both cases, configuration of a newly formed double bond was controlled to be in an $E$-form. The results of carboxylation of $\mathbf{1 c}$ in the absence of $\mathrm{ZnCl}_{2}$ (Scheme 4, eq. 1) strongly supported our initial hypothesis of the carboxylation/cyclization cascade shown in Scheme 1. However, the high regio- and Eselectivity observed in the reactions of $\mathbf{1 g}$ and $\mathbf{1 h}$ (Table 2, entries 4 and 5) suggest another possible reaction pathway. Montgomery and coworkers reported a nickelcatalyzed cyclization of allenyl aldehydes that involved an oxidative cyclization of the allene and aldehyde moieties to low-valent nickel species as the first step of the catalytic cycle. ${ }^{7 a}$ Allenyl aldehydes $\mathbf{1 g}$ or $\mathbf{1 h}$ would also be able to react with low-valent nickel species in a similar way before the reaction with $\mathrm{CO}_{2}$ (Scheme 5). To undergo such reaction, low-valent nickel species would be preferably placed at the opposite side of the " $R$ " group due to steric repulsion (Scheme 5, intermediate 7). Thus, oxidative cyclization from $\mathbf{7}$ would give oxa-nickelacycle intermediate 8 . Then insertion of $\mathrm{CO}_{2}$ into the nickel-carbon bond would proceed in a stereospecific manner to form 9, which would afford $\mathbf{3 g}$ or $\mathbf{3 h}$ after hydrolysis and esterification. This cyclization/carboxylation cascade pathway cannot be excluded in the reactions of other allenyl aldehydes. Thus, in the actual system, the reaction course might involve one or both cascades depending on the substrate used.

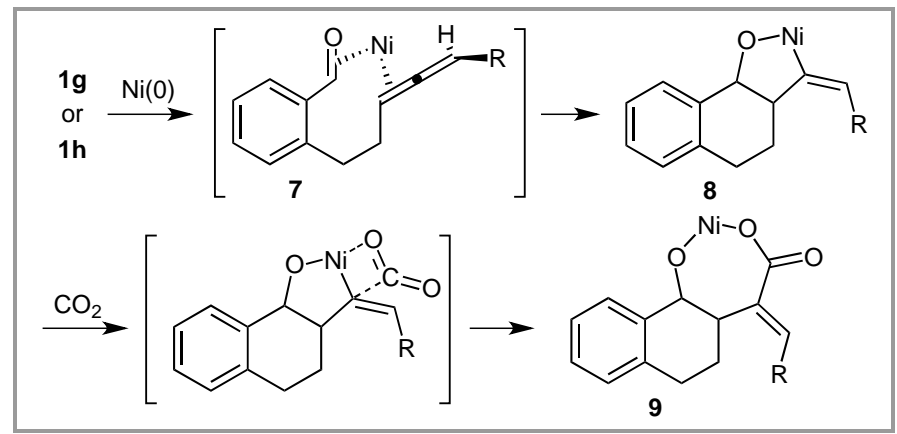

Scheme 5 Cyclization/Carboxylation Cascade

In summary, nickel-mediated cyclization of allenyl aldehydes that involved a $\mathrm{CO}_{2}$ incorporation process was developed. The reaction proceeds under mild conditions in a regioselective manner and provides a novel method for synthesis of bicyclic $\alpha$-methylene- $\gamma$-lactones. Further studies on expansion of the scope of this procedure are now in progress.
Supporting Information for this article is available online at http://www.thiemeconnect.com/ejournals/toc/synlett.

\section{References and Notes}

† Present address: Organometallic Chemistry Laboratory, RIKEN Advanced Science Institute, Hirosawa 2-1, Wako, Saitama 351-0198, Japan

(1) For reviews, see: (a) Braunstein, P.; Matt, D.; Nobel, D. Chem. Rev. 1988, 88, 747. (b) Gibson, D. H. Chem. Rev. 1996, 96, 2063. (c) Yin, X.; Moss, J. R. Coord. Chem. Rev. 1999, 181, 27. (d) Sakakura, T.; Choi, J.-C.; Yasuda, H. Chem. Rev. 2007, 107, 2365. (e) Z. Hou, T. Ohishi in Comprehensive Organometallic Chemistry III, Vol. 10 (Eds.: R. H. Crabtree, D. M. P. Mingos, I. Ojima), Elsevier, Oxford, 2007, pp. $537-555$.

(2) Recent examples for $\mathrm{CO}_{2}$ incorporation reactions, see: (a) Ukai, K.; Aoki, M.; Takaya, J. Iwasawa, N. J. Am. Chem. Soc. 2006, 128, 8706. (b) Greco, G. E.; Gleason, B. L.; Lowery, T. A.; Kier, M. J.; Hollander, L. B.; Gibbs, S. A.; Worthy, A. D. Org. Lett. 2007, 9, 3817. (c) Takaya, J.; Tadami, S.; Ukai, K.; Iwasawa, N. Org. Lett. 2008, 10, 2697. (d) Ohishi, T.; Nishiura, M.; Hou, Z. Angew. Chem. Int. Ed. 2008, 47, 5792. (e) Ochiai, H.; Jang, M.; Hirano, K.; Yorimitsu, H.; Oshima, K. Org. Lett. 2008, 10, 2681. (f) Yeung, C. S.; Dong, V. M. J. Am. Chem. Soc. 2008, 130, 7826. (g) Eghbali, N.; Eddy, J.; Anastas, P. T. J. Org. Chem. 2008, 73, 6932. (h) Kobayashi, K.; Kondo, Y. Org. Lett. 2009, 11, 2035. (i) Metzger, A.; Bernhardt, S.; Manolikakes, G.; Knochel, P. Angew. Chem., Int. Ed. 2010, 49, 4665. (j) Boogaerts, I. I. F.; Nolan, S. P. J. Am. Chem. Soc. 2010, 132, 8858. (k) Vechorkin, O.; Hirt, N.; Hu, X. Org. Lett. 2010, 12, 3567. (l) Zhang, L.; Cheng, J.; Ohishi, T.; Hou, Z. Angew. Chem. Int. Ed. 2010, 49, 8670. (m) Boogaerts, I. I. F.; Fortman, G. C.; Furst, M. R. C.; Cazin, C. S. J.; Nolan, S. P. Angew, Chem. Int. Ed. 2010, 49, 8674. (n) Fujihara, T.; Xu, T.; Semba, K.; Terao, J.; Tsuji, Y. Angew. Chem. Int. Ed. 2011, 50, 523. (o) Mizuno, H.; Takaya, J.; Iwasawa, N. J. Am. Chem. Soc. 2011, 133, 1251. For a review for nickel-mediated carboxylation, see: Takimoto, M.; Mori, M. in Modern Organonickel Chemistry (Ed. Y. Tamaru), Wiley-VCH, Weinheim, 2005, pp 205-223.

(4) (a) Takimoto, M.; Mori, M. J. Am. Chem. Soc. 2001, 123, 2895. (b) Takimoto, M.; Shimizu, K.; Mori, M. Org. Lett. 2001, 3, 3345. (c) Takimoto, M.; Mori, M. J. Am. Chem. Soc. 2002, 124, 10008. (d) Shimizu, K. Takimoto, M.; Mori, M. Org. Lett. 2003, 5, 2323. (e) Takimoto, M. Kawamura, M.; Mori, M. Org. Lett. 2003, 5, 2599. (f) Takimoto, M.; Kawamura, M.; Mori, M. Synthesis 2004, 791. (g) Shimizu, K.; Takimoto, M.; Sato, Y.; Mori, M. Org. Lett. 2005, 7, 195. (h) Takimoto, M.; Kawamura, M.; Mori, M.; Sato, Y. Synlett 2005, 2019. (i) Takimoto, M.; Nakamura, Y.; Kimura, K.; Mori, M. J. Am. Chem. Soc. 2004, 126, 5956. (j) Takimoto, M.; Mizuno, T.; Sato, Y.; Mori, M. Tetrahedron Lett. 2005, 46, 5173. (k) Takimoto, M.; Mizuno, T.; Mori, M.; Sato, Y. Tetrahedron 2006, 62, 7589.

(5) Other examples for transition metal-catalyzed $\mathrm{CO}_{2}$ incorporation reactions of allenes, see: (a) Döhring, A.; Jolly, P. W. Tetrahedron Lett. 1980, 21, 3021. (b) Aresta, M.; Quaranta, E.; Ciccarese, A. C1 Mol. Chem. 1985, 1, 283. (c) Sasaki, Y. J. Mol. Catal. 1989, 54, L9. (d) Dérien, S.; Clinet, J.-C.; Duñach, E.; Périchon, J. Synlett. 1990, 361. (e) Tsuda, T.; Yamamoto, T.; Saegusa, T. J. Organomet. Chem. 1992, 429, C46. (f) Aoki, M.; Kaneko, M.; Izumi, 
S.; Ukai, K.; Iwasawa, N. Chem. Commun. 2004, 2, 2568. (g) Aoki, M.; Izumi, S.; Kaneko, M.; Ukai, K.; Takaya, J.; Iwasawa, N. Org. Lett. 2007, 9, 1251. (h) Takaya, J.; Iwasawa, N. J. Am. Chem. Soc. 2008, 130, 15254 . (i) Takaya, J.; Iwasawa, N. Organometallics 2009, 28, 6636.

(6) Hoberg reported the formation of nickelacycles such as 2 by the reaction of allenes, $\mathrm{CO}_{2}$, and nickel(0) complex, see: Hoberg, H.; Oster, B. W. J. Organomet. Chem. 1984, 266, 321.

(7) Related examples for nickel-catalyzed inter- or intramolecular reactions between allene and aldehyde, see: (a) Montgomery, J.; Song, M. Org. Lett. 2002, 4, 4009. (b) Kang, S.-K.; Yoon, S.-K. Chem. Commun. 2002, 2634. (c) Ng, S.-S.; Jamison, T. F. J. Am. Chem. Soc. 2005, 127, 7320. (d) Montgomery, J.; Song, M. Tetrahedron 2005, 61, 11440. (e) S.-S. Ng.; Jamison, T. F. Tetrahedron 2006, 62, 11350.

(8) Oxidation of the mixture of trans- and cis-3a afforded the corresponding ketone as the sole product in high yield.

(9) Semmelhack reported a similar transformation involving an intramolecular nucleophilic addition of $\pi$-allylnickel bromide intermediate to aldehyde that formed a sevenmembered ring fused with $\alpha$-methylene- $\gamma$-lactone. The cisstereoselectivity observed in Semmelhack's example shows good accordance with our results: Semmelhack, M. F.; Wu, E. C. S. J. Am. Chem. Soc. 1976, 98, 3384. 


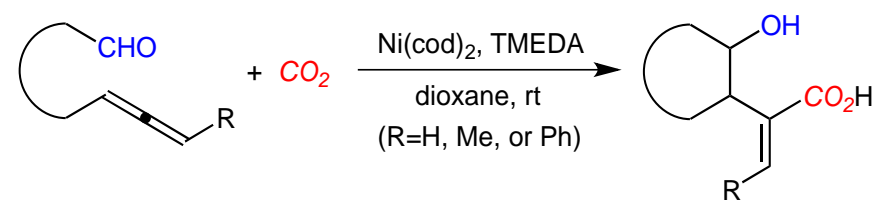

Carboxylation/Cyclization Cascade of Allenyl Aldehyde 